\title{
Bimetallic phosphides embedded in hierarchical P- doped carbon for sodium ion battery and hydrogen evolution reaction applications
}

\author{
Linjun Huang ${ }^{1 \dagger}$, Xinxin $\mathrm{Cao}^{1 \dagger}$, Anqiang Pan $^{1 *}$, Jing Chen ${ }^{1}$, Xiangzhong Kong ${ }^{1}$, Yongqiang Yang ${ }^{1}$, \\ Shuquan Liang ${ }^{*}$ and Guozhong $\mathrm{Cao}^{2}$
}

\begin{abstract}
Transition metal phosphides have been explored as promising active materials for sodium-ion batteries (SIBs) and hydrogen evolution reaction (HER) applications owing to their unique physical and chemical characteristics. However, they suffer from the drawbacks such as severe agglomeration, and sluggish reaction kinetics. Herein, bimetallic phosphides $\left(\mathrm{Ni}_{2} \mathrm{P} / \mathrm{ZnP}_{4}\right)$ embedded in $\mathrm{P}$-doped carbon hierarchical microspheres are demonstrated with robust structural integrity, fast charge transfer, and abundant active sites. As expected, the optimally structured $\mathrm{Ni}_{2} \mathrm{P} / \mathrm{ZnP}_{4}$ composite exhibits good electrochemical performance as an anode material in SIBs, including high specific capacity, good cycling stability and rate capability. Meanwhile, the $\mathrm{Ni}_{2} \mathrm{P} / \mathrm{ZnP}_{4}$ composite also exhibits excellent electrocatalytic performance for HER with a small

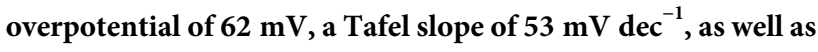
excellent stability.
\end{abstract}

Keywords: metal organic frameworks, phosphating, bimetallic composite, sodium-ion battery, hydrogen evolution reaction

\section{INTRODUCTION}

Nowadays, the fast consumption of fossil fuels and the accompanying serious environmental issues have forced researchers to explore clean, inexpensive, efficient, and sustainable energy storage and conversion technologies [1-4]. Sodium-ion batteries (SIBs) and hydrogen generation through electrocatalytic water splitting have been considered as two main alternatives due to their availability and environmental benignity [5-7]. Nevertheless, great challenges still hinder the further development of SIBs due to the inferior electrochemical performance, as well as the hydrogen evolution reaction (HER) owing to the rarity and prohibitive cost of the electrocatalysts (e.g., platinum group metal) [8-10]. In this respect, strategies need to be employed to improve sodium storage capability and quest inexpensive electrocatalysts, in which the most effective way is to engineer novel functional materials with unique micro-/nano-structures, complex chemical compositions, and natural abundance [11-15]. For example, Lu et al. [16] have developed a sequential etching, coordination reaction and pyrolysis strategy to synthesize Ni-doped FeP/C hollow nanorods with excellent HER activities in all-pH media owing to their component and structural benefits. We have recently synthesized bimetallic sulfides $\left(\mathrm{Co}_{9} \mathrm{~S}_{8} / \mathrm{ZnS}\right)$ embedded in hollow nitrogen-doped carbon nanosheets via a sulfidation of cobalt-zinc metal-organic frameworks (MOFs) and subsequent calcination [6]. We found that the abundant phase boundaries induced by two-phase construction may create numerous active sites and extrinsic defects for fast electron transportation and ion diffusion, which suggested that mixed-metal sulfides with complex compositions may improve the electrochemical activity compared with single-component ones. However, reasonable design of mixed-metal phosphides and further investigation of their performance in catalysis and batteries are rarely reported.

Recently, earth-abundant transition metal phosphides (TMPs) have shown great potential in batteries $[17,18]$, photocatalysis [19], electrocatalysis [20-22], due to their low cost, high electrical conductivity and activity. However, such kinds of materials suffer from large volumetric

\footnotetext{
${ }^{1}$ School of Material Science and Engineering, Central South University, Changsha 410083, China

${ }^{2}$ Department of Materials Science \& Engineering, University of Washington, Seattle, WA 98195, USA

$\dagger$ These authors contributed equally to this work.

* Corresponding authors (emails: pananqiang@csu.edu.cn (Pan A); lsq@csu.edu.cn (Liang S))
} 
strain, sluggish ion diffusion. Even worse, the structures of host materials are distorted due to the severe stacking and agglomeration, thus limiting their electrochemical durability and catalytic activity. Many effective strategies have been explored to enhance the performance of TMPs, such as nanostructure designed to buffer volume strain (e.g., $\mathrm{Ni}_{2} \mathrm{P}$ nanoarrays on nickel foam [21], and Ni-Co mixed metal phosphide nanoboxes [23]), hybrid with carbon matrix to improve the conductivity (e.g., $\mathrm{Cu}_{3} \mathrm{P}$ nanoparticles coated by a N,P-codoped carbon [24], and monodisperse $\mathrm{Ni}_{2} \mathrm{P}$ immobilized on $\mathrm{N}, \mathrm{P}$-codoped carbon nanosheets [25]), engineering of mixed-metal phosphides (e.g., Ni-Co-P hollow nanobricks [26], and $\mathrm{CoP} / \mathrm{FeP}$ porous microcubes[27]) to improve charge transfer. However, either of these strategies alone has a limited effect on the performance improvement for TMPs. Simultaneous integration of morphological design, conductive carbon modification, and compositional manipulation is expected to achieve better electrochemical performance and remedy these shortcomings.

In order to integrate the above-mentioned considerations, MOFs can be used as self-sacrificed templates to fabricate multicomponent phosphides which can effectively improve the conductivity of the material while retain its due activity $[28,29]$. At the same time, annealing at high temperature in inert atmosphere can effectively transform the organic framework into highly ordered three-dimensional (3D) porous carbon skeleton [30]. Herein, we report the in-situ formation of bimetallic phosphides nanocrystals embedded in hierarchical Pdoped carbon via a facile phosphatization of $\mathrm{Zn}$-doped Ni-MOF [31]. The synthesis process is schematically shown in Fig. 1. Bimetallic Ni-Zn MOF was applied as both self-sacrificing template and the precursor for the synthesis of bimetallic hybrid phosphides (designated as NZP@PC). Phosphorus-doped carbon matrix was formed simultaneously during high temperature carbonization. Benefiting from the abundant phase boundaries, robust structure, and highly conductive carbon skeleton, the composites show enhanced performance in both SIBs and HER. As SIBs anode materials, NZP@PC delivers a good rate capability with a specific capacity of $132.4 \mathrm{~mA} \mathrm{~h} \mathrm{~g}^{-1}$ at high current density of $2000 \mathrm{~mA} \mathrm{~g}^{-1}$, and excellent cyclic stability over 500 cycles at $500 \mathrm{~mA} \mathrm{~g}^{-1}$. As an electrocatalyst for HER, NZP@PC exhibits a small overpotential of $62 \mathrm{mV}$ and a Tafel slope of $53 \mathrm{mV} \mathrm{dec}^{-1}$.

\section{EXPERIMENTAL SECTION}

\section{Synthesis of Zn-doped Ni-MOF and pure Ni-MOF}

In typical synthesis of $\mathrm{Zn}$-doped $\mathrm{Ni}-\mathrm{MOF}, 1 \mathrm{mmol}$ of $p$ benzenedicarboxylic acid, $0.33 \mathrm{mmol}$ of $\mathrm{Ni}\left(\mathrm{NO}_{3}\right)_{2} \cdot 6 \mathrm{H}_{2} \mathrm{O}$, $0.33 \mathrm{mmol}$ of $\mathrm{ZnCl}_{2}$ were dissolved in $20 \mathrm{~mL}$ of $\mathrm{N}, \mathrm{N}$-dimethylformamide (DMF) with stirring at room temperature. After the solution became light green, uniform, and transparency, $2 \mathrm{~mL}$ of $0.4 \mathrm{~mol} \mathrm{~L}^{-1} \mathrm{NaOH}$ solution was added dropwise with continually stirring for $10 \mathrm{~min}$. After the solution became uniform, the mixture was transferred into a Teflon-lined stainless-steel autoclave with a capacity of $40 \mathrm{~mL}$ and kept in an electric oven at $100^{\circ} \mathrm{C}$ for $8 \mathrm{~h}$. After cooling down to room temperature, the product was collected and thoroughly washed several times with DMF and ethanol, respectively, and then dried under vacuum at $80^{\circ} \mathrm{C}$ for $12 \mathrm{~h}$. Then the $\mathrm{Zn}$-doped NiMOF was obtained, denoted as $\mathrm{Zn} / \mathrm{Ni}-\mathrm{MOF}$. For comparison, the pure Ni-MOF was prepared through a similar procedure mentioned above except for without adding $\mathrm{ZnCl}_{2}$.

\section{Synthesis of $\mathrm{Ni}_{2} \mathrm{P}-\mathrm{ZnP}_{4}$ composite (NZP@PC) and $\mathrm{Ni}_{2} \mathrm{P}$ (NP@PC)}

Firstly, the ground light green powders of $\mathrm{Zn} / \mathrm{Ni}-\mathrm{MOF}$

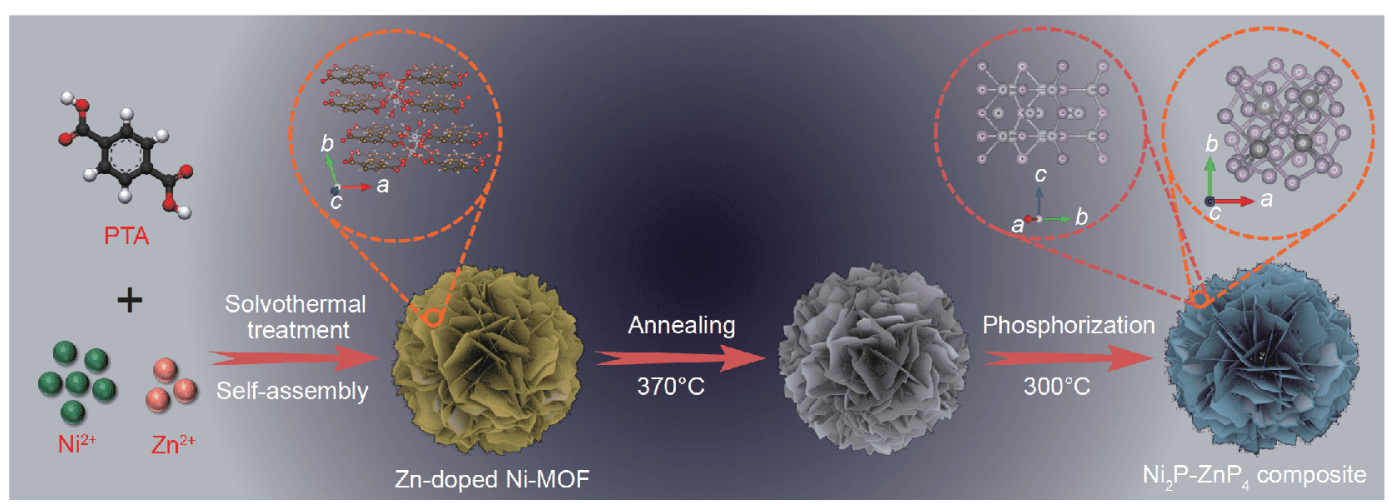

Figure 1 Schematic illustration of the formation of $\mathrm{Ni}_{2} \mathrm{P}-\mathrm{ZnP}_{4}$ composite coated by a P-doped porous carbon matrix (NZP@PC). 
and $\mathrm{Ni}-\mathrm{MOF}$ were placed in a tube furnace and annealed at $370^{\circ} \mathrm{C}$ for $1 \mathrm{~h}$ with a heating rate of $5^{\circ} \mathrm{C} \mathrm{min}{ }^{-1}$ under a flowing Ar. After pre-sintering, the MOFs initially decomposed and the samples were denoted as $\mathrm{Zn} / \mathrm{Ni}-\mathrm{MOF}$ $\mathrm{C}$ and Ni-MOF-C, respectively. The phosphorization process was then conducted by using $\mathrm{NaH}_{2} \mathrm{PO}_{2} \cdot \mathrm{H}_{2} \mathrm{O}$ as phosphorus source in a tube furnace. The mass ratio of $\mathrm{Zn} / \mathrm{Ni}-\mathrm{MOF}-\mathrm{C}$ (or Ni-MOF-C) to $\mathrm{NaH}_{2} \mathrm{PO}_{2} \cdot \mathrm{H}_{2} \mathrm{O}$ was about 1:10. Typically, Zn/Ni-MOF-C (or Ni-MOF-C) and $\mathrm{NaH}_{2} \mathrm{PO}_{2} \cdot \mathrm{H}_{2} \mathrm{O}$ were placed at two separate positions of the tube furnace, in which $\mathrm{NaH}_{2} \mathrm{PO}_{2} \cdot \mathrm{H}_{2} \mathrm{O}$ at the upstream and $\mathrm{Zn} / \mathrm{Ni}-\mathrm{MOF}-\mathrm{C}$ (or Ni-MOF-C) at the downstream. The samples were then subjected to heat treatment in tubular furnace at $300^{\circ} \mathrm{C}$ for $1 \mathrm{~h}$ under an ultrahigh purity Ar atmosphere with a heating rate of $1^{\circ} \mathrm{C} \min ^{-1}$ to obtain the final $\mathrm{Ni}_{2} \mathrm{P}-\mathrm{ZnP}_{4}$ composite (or $\mathrm{Ni}_{2} \mathrm{P}$ ). The obtained Pdoped carbon encapsulated phosphides are denoted as NZP@PC or NP@PC, respectively.

\section{Materials characterization}

The crystallographic information of the obtained samples was recorded by X-ray powder diffraction (XRD, Regaku D/Max-2500 with nonmonochromated $\mathrm{Cu}$ Ka radiation, $\lambda=1.5418 \AA$ ). Carbon content in the product was determined by using LECO CS-600 C/S analyzer. The property of carbon layer was analyzed by Raman spectrometer (LabRAM HR800). The microstructure and morphologies of the samples were characterized by fieldemission scanning electron microscope (FESEM, FEI Nova NanoSEM 230) at $10 \mathrm{kV}$ with energy dispersive Xray. And the transmission electron microscopy (TEM) images of these samples were observed by FEI Tecnai G2 F20 electron microscope working at an acceleration voltage of $200 \mathrm{kV}$. X-ray photoelectron spectroscopy (XPS, VG Escalab-250xi) measurements were also conducted to probe the electronic states of elements in the surface. The Nitrogen adsorption-desorption isotherms (Quantachrome Instruments) were recorded at $77 \mathrm{~K}$ for calculating the Brunauer-Emmett-Teller (BET) surface area and pore size.

\section{Electrode fabrication and electrochemical measurement}

Stainless-steel coin cells (CR2016) were made for electrochemical measurements. The working electrode was made by dispersing the as-prepared phosphides (NZP@PC or NP@PC) (85 wt.\%), conductive Super P (5 wt.\%), and polyvinylidene fluoride (PVDF) (10 wt.\%) in $\mathrm{N}$-methyl-2-pyrrolidone (NMP) solution to form a slurry. The homogeneous slurry was casted onto a copper current collector, and then was dried in a vacuum oven at $100^{\circ} \mathrm{C}$ overnight. The typical thickness of the electrode was $\sim 30 \mu \mathrm{m}$ with a mass loading of about $1.5 \pm$ $0.2 \mathrm{mg} \mathrm{cm}^{-2} \cdot 1 \mathrm{~mol} \mathrm{~L}^{-1} \mathrm{NaClO}_{4}$ in propylene carbonate (PC) with $5 \%$ fluoroethylene carbonate (FEC) was chosen as the electrolyte and the glass fiber membrane with thickness of $0.5 \mathrm{~mm}$ was used as the separator. All the cells were assembled in a glovebox (Mbraun, Germany) with ultra-high purity argon. Galvanostatic charge/discharge measurements were carried out in the potential range of $0.01-3.0 \mathrm{~V}$ at different current densities using a multichannel battery testing system (LAND CT2001A, China). Both the charge and discharge current density and specific capacity were calculated based on the mass of P-doped carbon encapsulated phosphides. Cyclic voltammetry $(\mathrm{CV})$ curves were recorded using an electrochemical workstation (CHI660E, China) between 0.01 and $3.0 \mathrm{~V}$. The electrochemical impedance spectroscopy (EIS) data of the electrodes were recorded on an electrochemical workstation (Metrohm Autolab-M204, Switzerland) in the frequency range of $100 \mathrm{kHz}$ to $0.01 \mathrm{~Hz}$.

The electrocatalytic activity of HER was evaluated in a typical three-electrode system attached to a CHI660C workstation at ambient temperature. A saturated calomel electrode $\left(\mathrm{Hg} / \mathrm{HgCl}_{2}\right.$ in saturated $\left.\mathrm{KCl}, \mathrm{SCE}\right)$ was used as the reference electrode and a platinum foil electrode was used as the counter electrode. The preparation method of the working electrodes containing investigated catalysts was as follows. The catalysts and PVDF powder were mixed in a weight ratio of 9:1 and dispersed in NMP to form uniform ink. Then the mixture was ultrasonicated for $20 \mathrm{~min}$ and spread homogenously onto $\mathrm{Ni}$ foam substrate of $\sim 1.0 \mathrm{~cm}^{2}$ in area. Finally, the as-prepared working electrode was dried at $60^{\circ} \mathrm{C}$ in vacuum. The loading amount of catalysts for each electrode was about $0.15 \mathrm{mg}$. Linear sweep voltammetry (LSV) was recorded at a scan rate of $5 \mathrm{mV} \mathrm{S}^{-1}$ to obtain the polarization curves. The polarization curves were replotted as overpotential vs. $\log$ current density to get Tafel plots for assessing the HER kinetics of investigated catalysts. The long-lifetime test was carried out by $i$ - $t$ curve at a constant working potential of $-1.27 \mathrm{~V}$ for $18 \mathrm{~h}$. All the data presented were corrected for $i R$ losses and background current. The electrochemical double-layer capacitance was determined from the CV curves measured in a potential range without redox processes according to the following equation: $C_{\mathrm{dl}}=I_{\mathrm{c}} / v$, where $C_{\mathrm{dl}}, I_{\mathrm{c}}$, and $v$ are the double-layer capacitance $\left(\mathrm{mF} \mathrm{cm}^{-2}\right)$ of the electroactive materials, charging current $\left(\mathrm{mA} \mathrm{cm}^{-2}\right)$, and scan rate $\left(\mathrm{mV} \mathrm{s}^{-1}\right)$, respectively. 

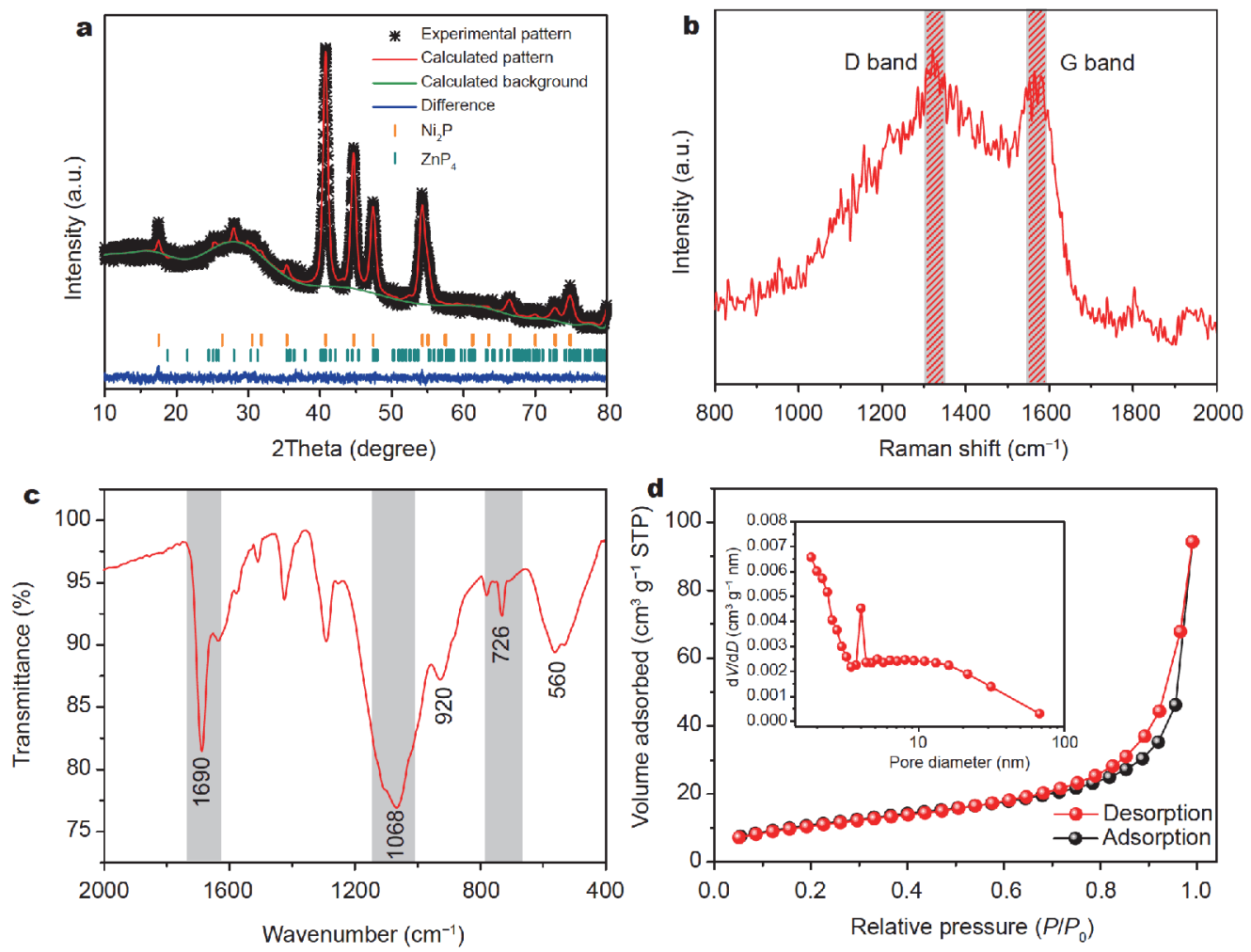

Figure 2 The chemical and physical characterizations of the as-prepared NZP@PC. (a) XRD patterns with Rietveld refinement. (b) Raman scattering spectrum. (c) FTIR spectrum. (d) Nitrogen adsorption-desorption isotherms and corresponding pore size distribution curve (the inset).

\section{RESULTS AND DISCUSSION}

The crystallographic information of $\mathrm{Zn} / \mathrm{Ni}-\mathrm{MOF}$ and NZP@PC were recorded by powder XRD measurement. As shown in Fig. S1, all the diffraction peaks of the $\mathrm{Zn} /$ $\mathrm{Ni}-\mathrm{MOF}$ correspond well to the layered topology of $\left[\mathrm{Ni}_{3}(\mathrm{OH})_{2}\left(\mathrm{C}_{8} \mathrm{H}_{4} \mathrm{O}_{4}\right)_{2}\left(\mathrm{H}_{2} \mathrm{O}\right)_{4}\right] \cdot 2 \mathrm{H}_{2} \mathrm{O}$ (CCDC \# 638866), which is highly consistent with the previous report [31]. Meanwhile, the XRD pattern with Rietveld refinement of the as-prepared NZP@PC composite is shown in Fig. 2a with all diffraction peaks well indexed to the hexagonal $\mathrm{Ni}_{2} \mathrm{P}$ phase (ICSD \# 43395), and tetragonal $\mathrm{ZnP}_{4}$ phase (ICSD \# 40428). The mass fractions of $\mathrm{Ni}_{2} \mathrm{P}$, and $\mathrm{ZnP}_{4}$ are 83.85 and $16.15 \mathrm{wt} . \%$, respectively, and the refined unit cell lattice parameters of these two phases are shown in Table S1. The carbon in NZP@PC was investigated by the Raman scattering spectrum (Fig. 2b). Two characteristic bands of carbonaceous materials located at $\sim 1327$ and $1571 \mathrm{~cm}^{-1}$ can be assigned to the D-band and G-band, respectively, indicating the presence and partial graphitization of carbon in the composite. Moreover, C-S analysis shows the mass content of carbon is about $33.28 \%$. Additionally, Fourier transform-infrared (FT-IR) spectrum was recorded as shown in Fig. 2c. The characteristic bands for $\mathrm{P}-\mathrm{O} / \mathrm{P}=\mathrm{O}$ stretching (around $1068 \mathrm{~cm}^{-1}$ ) and $\mathrm{C}-\mathrm{P}$ stretching (around $726 \mathrm{~cm}^{-1}$ ) are in accordance with the previous reports [24,32]. As-prepared composite shows characteristic $-\mathrm{COOH} /-\mathrm{CN}$ band centered at wavenumbers of around $1690 \mathrm{~cm}^{-1}$, indicating the existence of the functional groups in carbon skeleton [33]. Furthermore, nitrogen isothermal adsorption/desorption measurement was also carried out to further characterize the porous structure of the NZP@PC composite (Fig. 2d). The isotherm can be described as type II with type- $\mathrm{H} 3$ hysteresis loop, which can be linked to slit-shaped pores. The BET surface area of NZP@PC is measured to be $40.3 \mathrm{~cm}^{3} \mathrm{~g}^{-1}$ with mainly pore diameter below $30 \mathrm{~nm}$. The large surface area and narrow pore size distribution can provide substantial active sites for electrochemical reactions, and enhance electrolyte penetration for fast kinetics [34-36].

The detailed morphological and crystallographic properties of the products are elucidated through FESEM and TEM. As demonstrated in Fig. 3a, the prepared NZP@PC composite well inherits the hierarchical microsphere morphology of the $\mathrm{Zn} / \mathrm{Ni}-\mathrm{MOF}$ (Fig. S2) and the microspheres have an average diameter of $\sim 8 \mu \mathrm{m}$. 

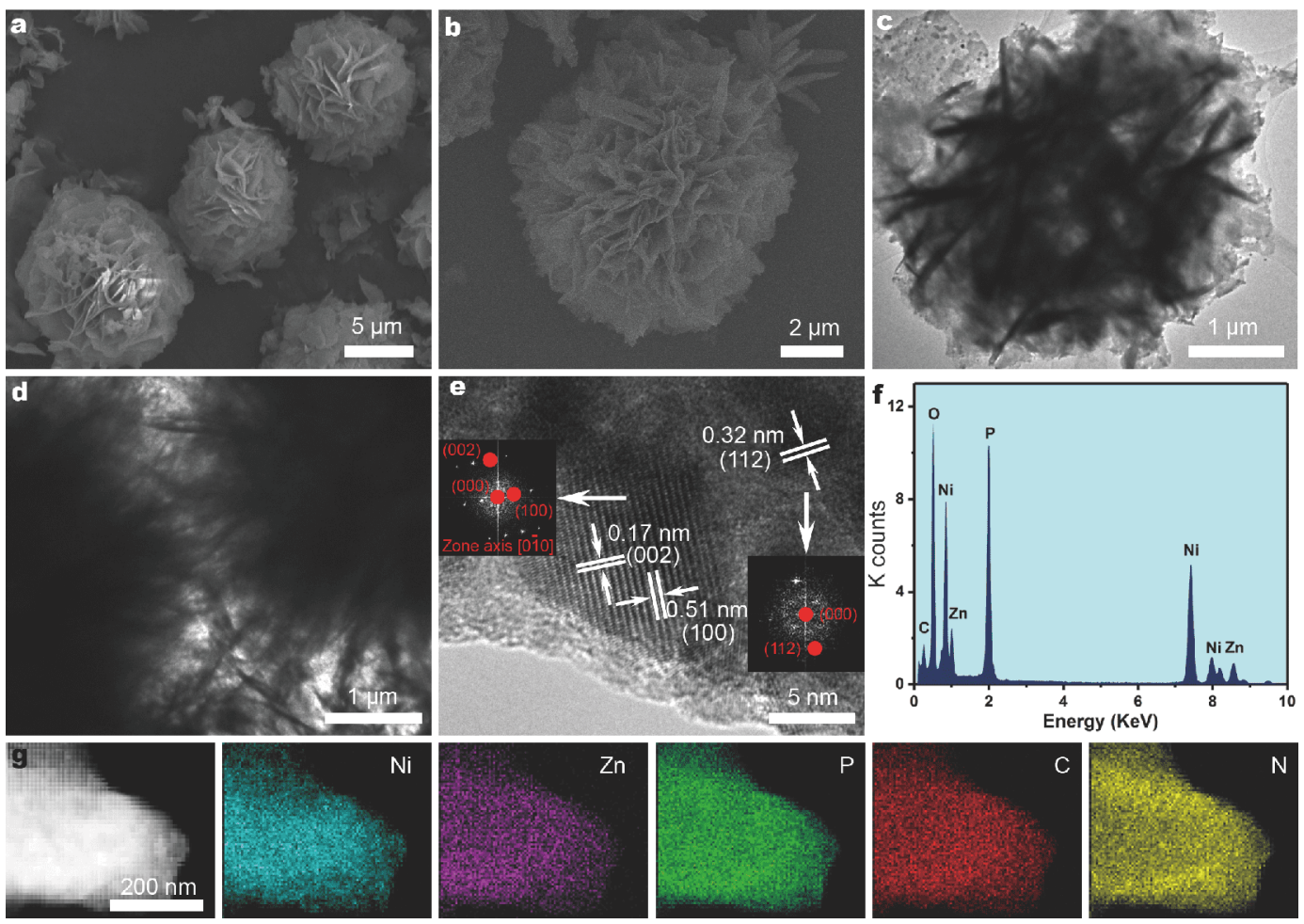

Figure 3 The morphological and microstructural characterizations of the as-prepared NZP@PC. (a, b) FESEM images. (c, d) TEM images. (e) HRTEM image and the corresponding FFT images of the selected regions, respectively. (f) STEM-EDX spectrum. (g) HAADF-STEM image and the corresponding EDS elemental maps.

The enlarged FESEM image (Fig. 3b) further reveals the detailed feature of the microsphere, which is composed of interconnected nanoflakes with apparent open spaces between them. The energy dispersive X-ray (EDX) elemental mapping images (Fig. S3) confirm the existence of $\mathrm{Ni}, \mathrm{Zn}$, and P. The TEM images (Fig. 3c, d) demonstrate the solid and dense interior of the $\mathrm{Zn} / \mathrm{Ni}-\mathrm{MOF}$ microspheres. The continuous nanoflakes are radially oriented and serve as building blocks to construct the hierarchical structure. The high-resolution TEM (HRTEM) image (Fig. 3e) was collected to further reveal the two-phase property. The fast Fourier transformation (FFT) image (inset of Fig. 3e) of the selected regions shows the diffraction spots of $\mathrm{Ni}_{2} \mathrm{P}$, and $\mathrm{ZnP}_{4}$, respectively. In addition, the lattice fringes in the nanocrystalline domains can be labeled by (100), (002) planes for $\mathrm{Ni}_{2} \mathrm{P}$ crystal, and (112) plane for $\mathrm{ZnP}_{4}$ crystal, respectively. Notably, a uniform thin carbon layer of around $3 \mathrm{~nm}$ is well decorated on the surface of the hybrid phosphides nanocrystals. The large amount of lattice mismatch and distortion between the $\mathrm{Ni}_{2} \mathrm{P}$ and $\mathrm{ZnP}_{4}$ crystalline domains may create more crystal defects and accessible active sites for ions storage and catalytic activity [37-39]. Furthermore, the high an- gle annular dark field scanning transmission electron microscopy (HAADF-STEM) image and the corresponding EDS elemental maps (Fig. 3g) show the homogenous distribution of $\mathrm{Ni}, \mathrm{Zn}, \mathrm{P}, \mathrm{C}$, and $\mathrm{O}$ elements in the independent nanoflake. The corresponding EDX spectrum (Fig. 3f) also confirms the existence of Ni, Zn, $\mathrm{P}, \mathrm{C}$, and $\mathrm{O}$ elements with low atomic percentage of $\mathrm{Zn}$ species, well consistent with the XRD results.

XPS was applied to ascertain the surface chemical composition and electronic structure of the as-prepared NZP@PC. Based on the survey spectrum in Fig. 4a, the NZP@PC composite is mainly composed of Ni, Zn, P, C, and $\mathrm{O}$ elements, corresponding well with the element mapping images (Fig. 3g). As depicted in Fig. 4b, the $\mathrm{Ni} 2 \mathrm{p}$ spectrum shows five prominent bands, corresponding to $\mathrm{Ni} 2 \mathrm{p}_{3 / 2}(853.5 \mathrm{eV})$ of $\mathrm{Ni}-\mathrm{P}$, and $\mathrm{Ni} 2 \mathrm{p}_{3 / 2}$ $(856.1 \mathrm{eV})$ and $\mathrm{Ni} 2 \mathrm{p}_{1 / 2}(874.1 \mathrm{eV})$ of $\mathrm{Ni}-\mathrm{O}$, respectively, with the bands at 861.6 and $879.4 \mathrm{eV}$ related to satellite bands [26]. As presented in the high-resolution $\mathrm{Zn} 2 \mathrm{p}$ spectrum (Fig. 4c), the two main peaks at around 1021.4 and $1045.2 \mathrm{eV}$ should be assigned to $\mathrm{Zn} 2 \mathrm{p}_{3 / 2}$ and $\mathrm{Zn} 2 \mathrm{p}_{1 / 2}$ of $\mathrm{Zn}^{2+}$, respectively [40]. The high resolution XPS of P 2p spectrum in Fig. $4 d$ is deconvoluted into three peaks 

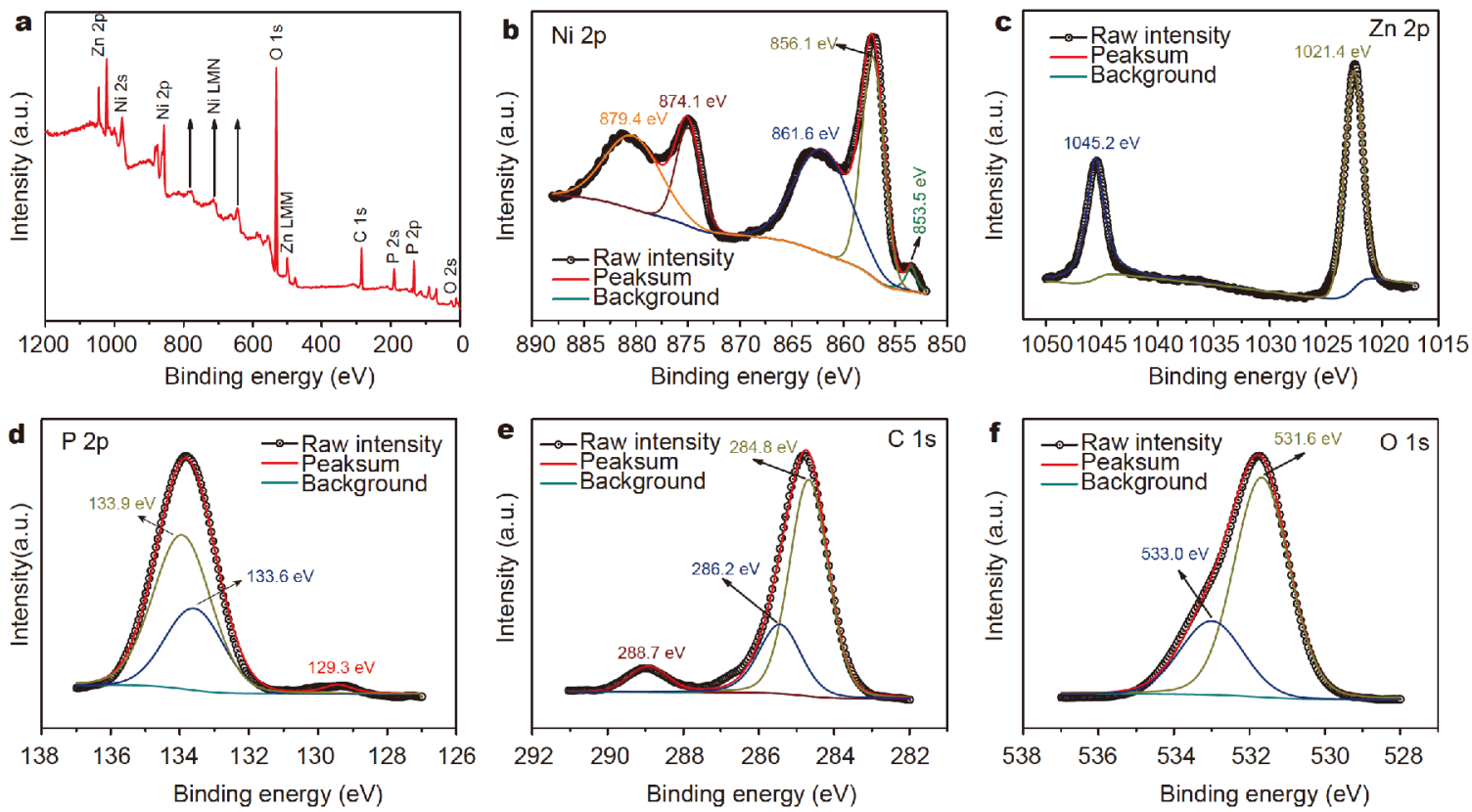

Figure 4 XPS spectra of the as-prepared NZP@PC. (a) XPS survey spectrum. (b) Ni 2p spectrum. (c) Zn 2p spectrum. (d) P 2p spectrum. (e) C 1s spectrum. (d) O 1s spectrum.

at $129.3,133.6$, and $133.9 \mathrm{eV}$, assigned to $\mathrm{C}-\mathrm{P}, \mathrm{P}-\mathrm{O}, \mathrm{P}=\mathrm{O}$ bonds, respectively [24]. The high resolution XPS of C 1s spectrum (Fig. 4e) can be resolved into three components centered at $284.8,286.2$, and $288.7 \mathrm{eV}$. The main peak located at $284.8 \mathrm{eV}$ corresponds to the graphite-like $\mathrm{sp}^{2} \mathrm{C}$ [24]. The small peaks at 286.2 and $288.7 \mathrm{eV}$ can be ascribed to the $\mathrm{C}-\mathrm{P}$ and $\mathrm{CO}$ type bonds, respectively, which originate from the substitutional doping of $\mathrm{P}[24,25]$. The P-doped carbon matrix can improve the electronic conductivity of electrode material and provide more active sites [41]. The oxidized species (Fig. 4f) associated with the $\mathrm{Ni}-\mathrm{O}, \mathrm{P}-\mathrm{O}, \mathrm{P}=\mathrm{O}$, and $\mathrm{CO}$-type bonds can be ascribed to the incomplete phosphorization or/and slightly oxidized surface of NZP@PC under ambient conditions, which are consistent well with the previous reports $[21,25,26,36]$.

For comparison, similar experiments without adding $\mathrm{ZnCl}_{2}$ were carried out and pure Ni-MOF was obtained. After the sequential pre-decomposition and phosphatization, a $\mathrm{P}$-doped carbon encapsulated $\mathrm{Ni}_{2} \mathrm{P}$ (designated as NP@PC) was obtained. In the absence of $\mathrm{ZnCl}_{2}$, only bulk particles morphology was obtained (Fig. S4d, e). The chemical and physical characterizations of the NP@PC are shown in Fig. S4a-c. Pure $\mathrm{Ni}_{2} \mathrm{P}$ with good crystallinity was obtained and Raman characteristic peaks of carbonaceous material were detected. The single-crystalline nature of $\mathrm{Ni}_{2} \mathrm{P}$ was confirmed (Fig. S4f) and the uniform distribution of $\mathrm{Ni}, \mathrm{P}, \mathrm{C}$, and $\mathrm{O}$ was demonstrated by the HAADF-STEM image and the corresponding EDS elemental maps (Fig. S4g).

The NZP@PC or NP@PC was assembled into half-cells to evaluate the electrochemical performance as anode materials for SIBs as shown in Fig. 5. Fig. 5a shows the cycling performance of NZP@PC and NP@PC electrodes at a current density of $100 \mathrm{~mA} \mathrm{~g}^{-1}$ in the voltage range of 0.01-3.0 V versus $\mathrm{Na}^{+} / \mathrm{Na}$ and Fig. $5 \mathrm{~b}$ shows the corresponding charge-discharge voltage profiles. The NZP@PC electrode exhibits the initial discharge and charge capacities of 701 and $513 \mathrm{~mA} \mathrm{~h} \mathrm{~g}^{-1}$ at $100 \mathrm{~mA} \mathrm{~g}^{-1}$, respectively, corresponding to a high Coulombic efficiency of $73.1 \%$. This initial irreversibility may be attributed to the formation of the solid electrolyte interphase (SEI) film and other undesirable side reactions [42]. A high reversible discharge capacity of $436 \mathrm{~mA} \mathrm{~h} \mathrm{~g}^{-1}$ is achieved in the second cycle, which maintains $249 \mathrm{~mA} \mathrm{~h} \mathrm{~g}^{-1}$ even after 100 cycles (Fig. 5a), suggesting the good cycling stability of NZP@PC. In contrast, the NP@PC electrode exhibits much inferior cycling performance (an initial Coulombic efficiency of $68.2 \%$ and a capacity retention of $35.2 \%$ from the second cycle to the $100^{\text {th }}$ ). Fig. S5 shows the CV curves of the initial three cycles for NZP@PC electrode at a scan rate of $0.1 \mathrm{mV} \mathrm{s}^{-1}$ in the voltage range of $0.01-3.0 \mathrm{~V}$ versus $\mathrm{Na}^{+} / \mathrm{Na}$. In the first cathodic sweep, several broad peaks can be ascribed 

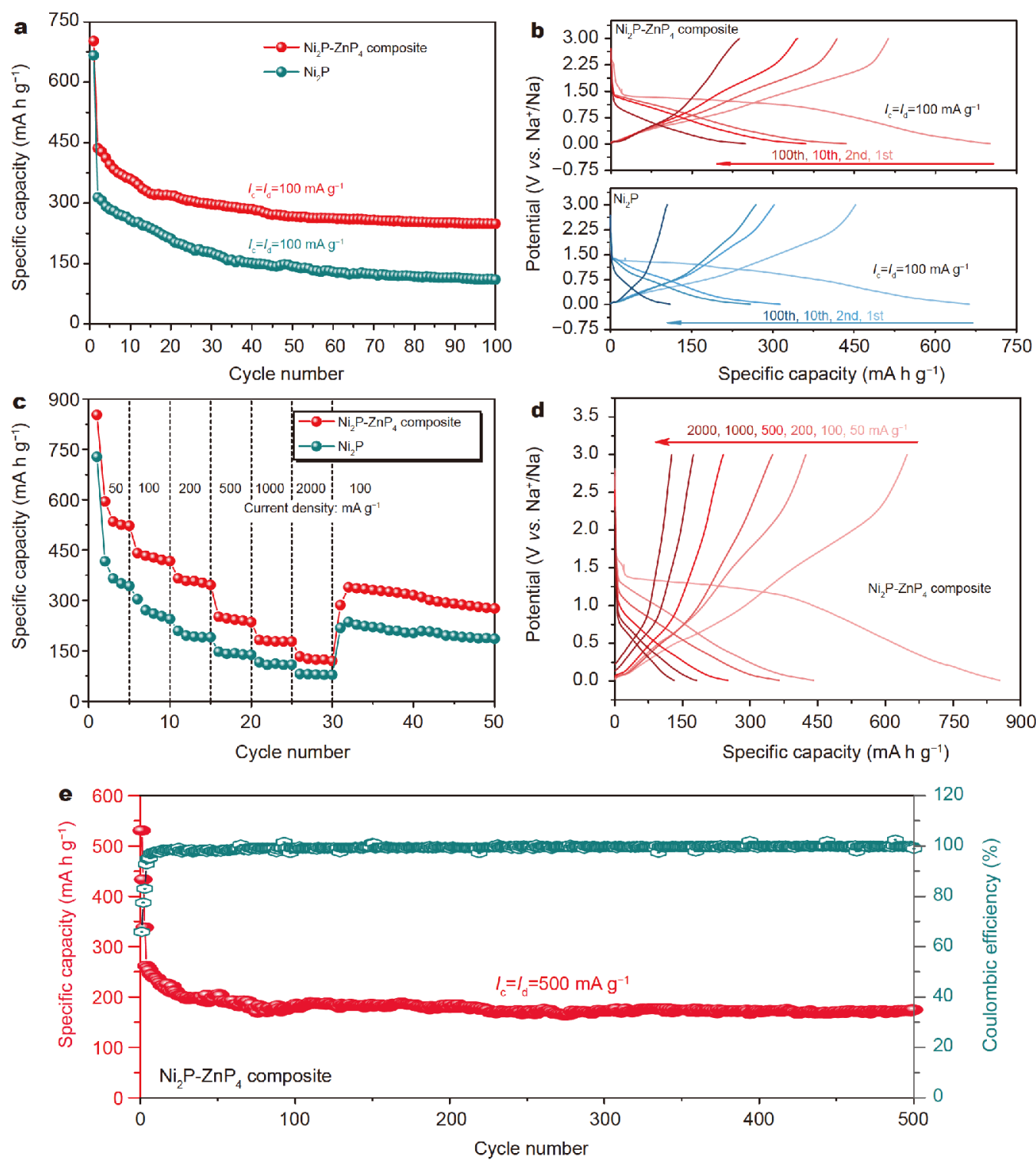

Figure 5 The electrochemical characterizations of the as-prepared $\mathrm{Ni}_{2} \mathrm{P}-\mathrm{ZnP}_{4}$ composite (NZP@PC) and $\mathrm{Ni}_{2} \mathrm{P}(\mathrm{NP} @ \mathrm{PC})$ as a half-cell anode in the potential range of $0.01-3.0 \mathrm{~V}$ versus $\mathrm{Na}^{+} / \mathrm{Na}$. (a) Cycling performance at the current density of $100 \mathrm{~mA} \mathrm{~g}^{-1}$. (b) Galvanostatic charge/discharge profiles of selected cycles at $100 \mathrm{~mA} \mathrm{~g}^{-1}$. (c) Rate performance at various current densities from 50 to $2000 \mathrm{~mA} \mathrm{~g}^{-1}$. (d) Galvanostatic charge/discharge profiles of NZP@PC at various current densities. (e) Long-term cycling performance and Coulombic efficiency of the NZP@PC electrode at $500 \mathrm{~mA} \mathrm{~g}$ for 500 cycles.

to the conversion reaction forming the metal element and $\mathrm{Na}_{3} \mathrm{P}$, the alloying reaction forming the $\mathrm{NaZn}_{13}$, and the formation of SEI film [32,43-45]. As for anodic scan, the peaks can be attributed to the reversible oxidation reaction of the metal element into mixed-metal phosphides [43-46]. The rate capability of the NZP@PC and NP@PC electrodes is compared and the representative charge/ discharge voltage profiles at various current densities are provided (Fig. 5d and Fig. S6). As shown in Fig. 5c, the discharge capacity of the NZP@PC electrode in the second cycle at $50 \mathrm{~mA} \mathrm{~g}^{-1}$ is $595 \mathrm{~mA} \mathrm{~h} \mathrm{~g}^{-1}$, much higher than that of NP@PC (417 mA h g $\left.{ }^{-1}\right)$ in the same cycle. Along with the increase of the current density from $100 \mathrm{~mA} \mathrm{~g}^{-1}$ to $2000 \mathrm{~mA} \mathrm{~g}^{-1}$, the specific capacity of the NZP@PC electrode decreases from 441 to $133 \mathrm{~mA} \mathrm{~h} \mathrm{~g}^{-1}$. The decline of capacity with increasing charge/discharge current density is routinely observable for mass transport limiting process. The specific capacity returns to $339 \mathrm{~mA} \mathrm{~h} \mathrm{~g}^{-1}$ 
when the current density comes back to $100 \mathrm{~mA} \mathrm{~g}^{-1}$, implying the much superior kinetics of NZP@PC as compared with that of NP@PC. Fig. 5e shows the longterm cycling performance and Coulombic efficiency of the NZP@PC electrode at high current density of $500 \mathrm{~mA} \mathrm{~g}^{-1}$. The $4^{\text {th }}$ discharge capacity of NZP@PC anode is $262 \mathrm{~mA} \mathrm{~h} \mathrm{~g}^{-1}$. After 500 cycles, the electrode can deliver a specific capacity of $175 \mathrm{~mA} \mathrm{~h} \mathrm{~g}^{-1}$ with a capacity retention of $66.8 \%$.

The Nyquist plots (Fig. S7) show that the charge transfer resistance $\left(R_{\mathrm{ct}}\right)$ of the NZP@PC electrode after $1^{\text {st }}$ and $5^{\text {th }}$ cycles are 288 and $279 \Omega$, respectively, indicating the fast charge transfer kinetics. In addition, the hierarchical structure can be well maintained without obvious pulverization or size variation after discharge and charge (Fig. S8). The nanoflakes-constructed hierarchical microspheres of NZP@PC with abundant phase boundaries can facilitate the penetration of electrolyte and shorten the diffusion path of ions, thereby achieving fast reaction kinetics. Table S2 gives a list of previously reported transition-metal phosphides as anode materials for SIBs, which indicates the good electrochemical performance of the NZP@PC electrode.
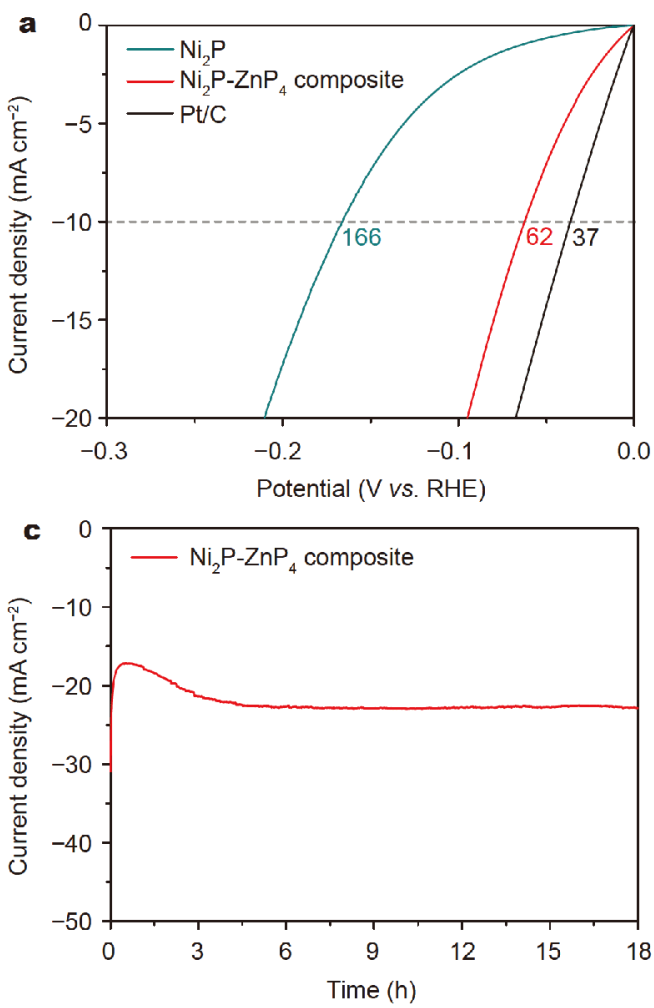

We further investigated the HER activity of NZP@PC and NP@PC for water splitting in $1 \mathrm{~mol} \mathrm{~L}^{-1} \mathrm{KOH}$ aqueous solution, with commercial $\mathrm{Pt} / \mathrm{C}$ electrode for comparison. Fig. 6a shows the polarization curves with $i R$ correction. The NP@PC requires an overpotential of about $166 \mathrm{mV}$ to reach a current density of $10 \mathrm{~mA} \mathrm{~cm}^{-2}$. In sharp contrast, the NZP@PC exhibits excellent electrocatalytic activity in the HER and deliveries a current density of $10 \mathrm{~mA} \mathrm{~cm}^{-2}$ at an overpotential of $62 \mathrm{mV}$, only $25 \mathrm{mV}$ larger than that of $\mathrm{Pt} / \mathrm{C}$ electrode. The corresponding Tafel plots based on the LSV curves are presented in Fig. $6 \mathrm{~b}$. These linear regions of Tafel plots are fitted to the Tafel equation $(\eta=b \log j+a$, where $b$ is the Tafel slope). The Tafel slope of NZP@PC $\left(53 \mathrm{mV} \mathrm{dec}^{-1}\right)$ is smaller than that of the NP@PC $\left(103 \mathrm{mV} \mathrm{dec}^{-1}\right)$, implying the favorable HER kinetics for NZP@PC hierarchical microspheres. The Tafel slope of NZP@PC composite shows that the hydrogen evolution process of this material might be based on the Volmer-Heyrovsky mechanism [47]. These results indicate the electrocatalytic HER activity of the NZP@PC is better than that of the NP@PC and comparable to those of transition-metal-based phosphides catalysts (Table S3). In addition, the dur-
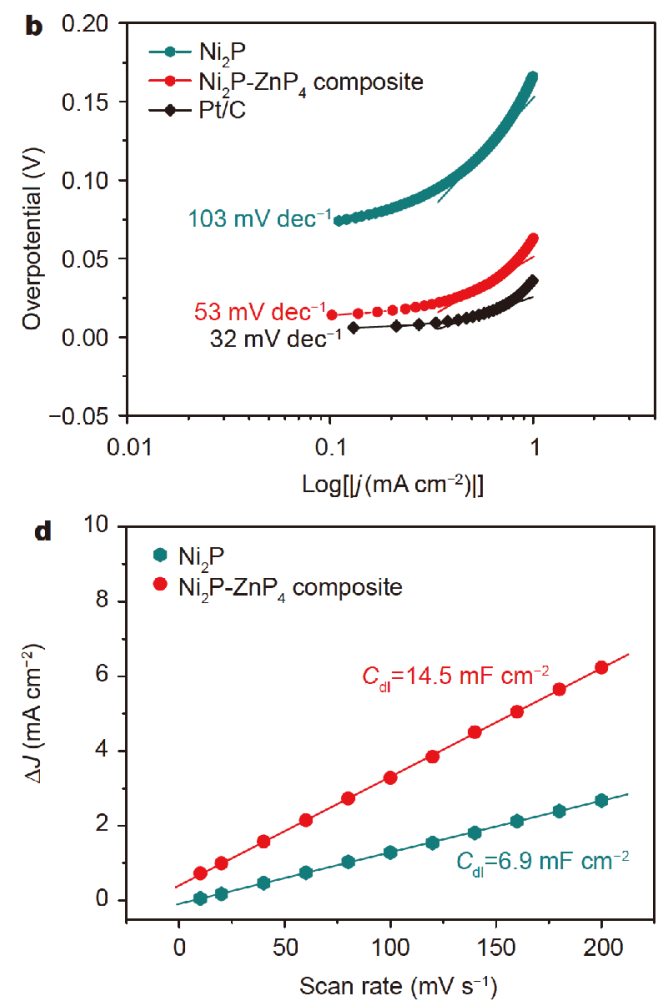

Figure 6 The electrocatalytic performances of the as-prepared $\mathrm{Ni}_{2} \mathrm{P}-\mathrm{ZnP}_{4}$ composite (NZP@PC) and $\mathrm{Ni}_{2} \mathrm{P}(\mathrm{NP} @ \mathrm{PC})$. (a) Polarization curves and (b) Tafel plots of bare NZP@PC, NP@PC, and Pt/C for HER in 1 mol L ${ }^{-1} \mathrm{KOH}$. (c) The long-term durability test of NZP@PC at an overpotential of $150 \mathrm{mV}$. (d) Estimation of $C_{\mathrm{dl}}$ by plotting the current density variation against scan rate to fit a linear regression. 
ability of catalysts is also critical for practical applications. As shown in Fig. $6 c$, the electrode was operated at a certain potential to obtain the time-dependent current. It can be seen that the current maintain stability within $18 \mathrm{~h}$ of continuous measurement, which demonstrates the good stability of the hierarchical NZP@PC microspheres during the HER process. By the way, a minor current rise in the first hour may be a result of the activation process of catalyst in the alkaline electrolyte [48,49]. At the end of the measurement, the obtained polarization curve is close to the initial one, demonstrating the strong durability of the catalyst (Fig. S9). Besides, SEM images (Fig. S10b-d) indicate that this catalyst electrode still maintains its morphology after durability test. Ex situ XRD analysis (Fig. S10a) of this NZP@PC electrode further suggests the excellent phase stability. Furthermore, the double-layer capacitances $\left(C_{\mathrm{dl}}\right)$ were evaluated by $\mathrm{CV}$ (Fig. S11) in a voltage range from 0.3 to $0.4 \mathrm{~V}$ to measure the electrochemically active surface area (ECSA) of the material. The larger ECSA represents the more effective utilization of catalytic active sites. The $C_{\mathrm{dl}}$ of NZP@PC is determined to be $14.5 \mathrm{mF} \mathrm{cm}^{-2}$ (Fig. 6d), higher than that of NP@PC $\left(6.9 \mathrm{mF} \mathrm{cm}^{-2}\right)$, indicating that the $\mathrm{Ni}_{2} \mathrm{P}-\mathrm{ZnP}_{4}$ composite has higher accessible active surface areas than $\mathrm{Ni}_{2} \mathrm{P}$. The $\mathrm{P}$-doped carbon can greatly enhance the electrical conductivity of the composite (Fig. S12). Compared with NP@PC, the phase boundaries of NZP@PC provide more active sites to achieve higher HER activity. Moreover, the unique hierarchical architecture can expose these active sites and accelerate mass transfer, resulting in the faster kinetics. The integration of advantages from hierarchical architecture, P-doped carbon modification, and compositional manipulation can enhance HER performance remarkably.

\section{CONCLUSIONS}

In summary, we have successfully developed a facile strategy for the synthesis of bimetallic phosphides nanocrystals embedded in P-doped carbon hierarchical microspheres via sequential pre-decomposition and phosphatization processes of $\mathrm{Zn}$-doped Ni-MOF. Compared with the irregularly bulk particles of monometallic phosphide, the hierarchical porous micro/nano architecture along with P-doped carbon encapsulation of bimetallic phosphides can provide favorable ion and electron transportation, as well as robust structural integrity. The abundant phase boundaries induced by twophase construction can also expose the electrochemically active sites for $\mathrm{Na}$ ions storage and catalytic reaction. As a result, the optimum NZP@PC exhibits good electro- chemical performance for SIBs and excellent electrocatalytic performance for HER. Such a synergistic integration of compositional manipulation with architectural regulation may also be extended to other functional materials for future applications.

Received 13 April 2019; accepted 18 July 2019;

published online 6 August 2019

1 Yabuuchi N, Kubota K, Dahbi M, et al. Research development on sodium-ion batteries. Chem Rev, 2014, 114: 11636-11682

2 Xia W, Mahmood A, Zou R, et al. Metal-organic frameworks and their derived nanostructures for electrochemical energy storage and conversion. Energy Environ Sci, 2015, 8: 1837-1866

3 Massé RC, Uchaker E, Cao G. Beyond Li-ion: Electrode materials for sodium- and magnesium-ion batteries. Sci China Mater, 2015, 58: 715-766

4 Xin S, Chang Z, Zhang X, et al. Progress of rechargeable lithium metal batteries based on conversion reactions. Nat Sci Rev, 2016, nww078

5 Cao X, Pan A, Liu S, et al. Chemical synthesis of 3D graphene-like cages for sodium-ion batteries applications. Adv Energy Mater, 2017, 7: 1700797

6 Fang G, Wu Z, Zhou J, et al. Observation of pseudocapacitive effect and fast ion diffusion in bimetallic sulfides as an advanced sodiumion battery anode. Adv Energy Mater, 2018, 8: 1703155

7 Massé RC, Liu C, Li Y, et al. Energy storage through intercalation reactions: Electrodes for rechargeable batteries. Nat Sci Rev, 2017, 4: $26-53$

8 Barpanda P, Oyama G, Nishimura SI, et al. A 3.8-V earth-abundant sodium battery electrode. Nat Commun, 2014, 5: 4358

9 Zhang Y, Foster CW, Banks CE, et al. Graphene-rich wrapped petal-like rutile $\mathrm{TiO}_{2}$ tuned by carbon dots for high-performance sodium storage. Adv Mater, 2016, 28: 9391-9399

10 Guan BY, Yu L, Lou XWD. General synthesis of multishell mixedmetal oxyphosphide particles with enhanced electrocatalytic activity in the oxygen evolution reaction. Angew Chem Int Ed, 2017, 56: $2386-2389$

11 Zhu CR, Gao D, Ding J, et al. TMD-based highly efficient electrocatalysts developed by combined computational and experimental approaches. Chem Soc Rev, 2018, 47: 4332-4356

12 Wu F, Zhao C, Chen S, et al. Multi-electron reaction materials for sodium-based batteries. Mater Today, 2018, 21: 960-973

13 Cao X, Pan A, Yin B, et al. Nanoflake-constructed porous $\mathrm{Na}_{3} \mathrm{~V}_{2}\left(\mathrm{PO}_{4}\right)_{3} / \mathrm{C}$ hierarchical microspheres as a bicontinuous cathode for sodium-ion batteries applications. Nano Energy, 2019, 60: 312-323

14 An X, Yang H, Wang Y, et al. Hydrothermal synthesis of coherent porous $\mathrm{V}_{2} \mathrm{O}_{3}$ /carbon nanocomposites for high-performance lithium- and sodium-ion batteries. Sci China Mater, 2017, 60: 717727

15 Luo Z, Liu S, Cai Y, et al. Nitrogen/sulfur co-doped hollow carbon nanofiber anode obtained from polypyrrole with enhanced electrochemical performance for Na-ion batteries. Sci Bull, 2018, 63: $126-132$

16 Lu XF, Yu L, Lou XWD. Highly crystalline Ni-doped FeP/carbon hollow nanorods as all-pH efficient and durable hydrogen evolving electrocatalysts. Sci Adv, 2019, 5: eaav6009

17 Ge X, Li Z, Yin L. Metal-organic frameworks derived porous core/ 
shell CoP@C polyhedrons anchored on 3D reduced graphene oxide networks as anode for sodium-ion battery. Nano Energy, 2017, 32: 117-124

18 Dong C, Guo L, He Y, et al. Sandwich-like $\mathrm{Ni}_{2} \mathrm{P}$ nanoarray/nitrogen-doped graphene nanoarchitecture as a high-performance anode for sodium and lithium ion batteries. Energy Storage Mater, 2018, 15: 234-241

19 Callejas JF, McEnaney JM, Read CG, et al. Electrocatalytic and photocatalytic hydrogen production from acidic and neutral-pH aqueous solutions using iron phosphide nanoparticles. ACS Nano, 2014, 8: 11101-11107

20 Zhang $\mathrm{X}, \mathrm{Gu} \mathrm{W}$, Wang E. Self-supported ternary $\mathrm{Co}_{0.5} \mathrm{Mn}_{0.5} \mathrm{P} /$ carbon cloth (CC) as a high-performance hydrogen evolution electrocatalyst. Nano Res, 2016, 10: 1001-1009

21 Tang C, Zhang R, Lu W, et al. Energy-saving electrolytic hydrogen generation: $\mathrm{Ni}_{2} \mathrm{P}$ nanoarray as a high-performance non-noblemetal electrocatalyst. Angew Chem Int Ed, 2017, 56: 842-846

22 Tabassum H, Guo W, Meng W, et al. Metal-organic frameworks derived cobalt phosphide architecture encapsulated into $\mathrm{B} / \mathrm{N}$ codoped graphene nanotubes for all $\mathrm{pH}$ value electrochemical hydrogen evolution. Adv Energy Mater, 2017, 7: 1601671

23 He P, Yu XY, Lou XWD. Carbon-incorporated nickel-cobalt mixed metal phosphide nanoboxes with enhanced electrocatalytic activity for oxygen evolution. Angew Chem Int Ed, 2017, 56: 3897-3900

24 Wang R, Dong XY, Du J, et al. MOF-derived bifunctional $\mathrm{Cu}_{3} \mathrm{P}$ nanoparticles coated by a N,P-codoped carbon shell for hydrogen evolution and oxygen reduction. Adv Mater, 2018, 30: 1703711

25 Shi S, Li Z, Sun Y, et al. A covalent heterostructure of monodisperse $\mathrm{Ni}_{2} \mathrm{P}$ immobilized on $\mathrm{N}, \mathrm{P}$-co-doped carbon nanosheets for high performance sodium/lithium storage. Nano Energy, 2018, 48: $510-517$

26 Hu E, Feng Y, Nai J, et al. Construction of hierarchical Ni-Co-P hollow nanobricks with oriented nanosheets for efficient overall water splitting. Energy Environ Sci, 2018, 11: 872-880

27 Li Z, Zhang L, Ge X, et al. Core-shell structured $\mathrm{CoP} / \mathrm{FeP}$ porous microcubes interconnected by reduced graphene oxide as high performance anodes for sodium ion batteries. Nano Energy, 2017, 32: 494-502

28 Wang L, Han Y, Feng X, et al. Metal-organic frameworks for energy storage: Batteries and supercapacitors. Coord Chem Rev, 2016, 307: 361-381

29 Zhu QL, Xu Q. Metal-organic framework composites. Chem Soc Rev, 2014, 43: 5468-5512

30 Jiang HL, Liu B, Lan YQ, et al. From metal-organic framework to nanoporous carbon: Toward a very high surface area and hydrogen uptake. J Am Chem Soc, 2011, 133: 11854-11857

31 Yang J, Zheng C, Xiong P, et al. Zn-doped Ni-MOF material with a high supercapacitive performance. J Mater Chem A, 2014, 2: 19005-19010

32 Liu S, Feng J, Bian X, et al. A controlled red phosphorus@Ni-P core@shell nanostructure as an ultralong cycle-life and superior high-rate anode for sodium-ion batteries. Energy Environ Sci, 2017, 10: 1222-1233

33 Fang Y, Xiao L, Qian J, et al. 3D graphene decorated $\mathrm{NaTi}_{2}\left(\mathrm{PO}_{4}\right)_{3}$ microspheres as a superior high-rate and ultracycle-stable anode material for sodium ion batteries. Adv Energy Mater, 2016, 6: 1502197

34 Chen J, Pan A, Wang Y, et al. Hierarchical mesoporous MoSe $e_{2}$ CoSe/N-doped carbon nanocomposite for sodium ion batteries and hydrogen evolution reaction applications. Energy Storage
Mater, 2019

35 Von Lim Y, Huang S, Zhang Y, et al. Bifunctional porous iron phosphide/carbon nanostructure enabled high-performance sodium-ion battery and hydrogen evolution reaction. Energy Storage Mater, 2018, 15: 98-107

36 Yin B, Cao X, Pan A, et al. Encapsulation of $\operatorname{CoS}_{x}$ nanocrystals into $\mathrm{N} / \mathrm{S}$ co-doped honeycomb-like 3D porous carbon for high-performance lithium storage. Adv Sci, 2018, 5: 1800829

37 Wang S, Yang Y, Quan W, et al. $\mathrm{Ti}^{3+}$-free three-phase $\mathrm{Li}_{4} \mathrm{Ti}_{5} \mathrm{O}_{12} /$ $\mathrm{TiO}_{2}$ for high-rate lithium ion batteries: Capacity and conductivity enhancement by phase boundaries. Nano Energy, 2017, 32: 294301

38 Liang S, Cao X, Wang Y, et al. Uniform $8 \mathrm{LiFePO}_{4} \cdot \mathrm{Li}_{3} \mathrm{~V}_{2}\left(\mathrm{PO}_{4}\right)_{3} / \mathrm{C}$ nanoflakes for high-performance Li-ion batteries. Nano Energy, 2016, 22: 48-58

39 Cao X, Pan A, Zhang Y, et al. Nanorod-nanoflake interconnected LiMnPO ${ }_{4} \cdot \mathrm{Li}_{3} \mathrm{~V}_{2}\left(\mathrm{PO}_{4}\right)_{3} / \mathrm{C}$ composite for high-rate and long-life lithium-ion batteries. ACS Appl Mater Interfaces, 2016, 8: 2763227641

40 Tang C, Wei X, Cai X, et al. ZnSe microsphere/multiwalled carbon nanotube composites as high-rate and long-life anodes for sodiumion batteries. ACS Appl Mater Interfaces, 2018, 10: 19626-19632

41 Hou H, Shao L, Zhang Y, et al. Large-area carbon nanosheets doped with phosphorus: A high-performance anode material for sodium-ion batteries. Adv Sci, 2017, 4: 1600243

42 Wang X, Chen K, Wang G, et al. Rational design of three-dimensional graphene encapsulated with hollow FeP@carbon nanocomposite as outstanding anode material for lithium ion and sodium ion batteries. ACS Nano, 2017, 11: 11602-11616

43 Miao X, Yin R, Ge X, et al. $\mathrm{Ni}_{2}$ P@carbon core-shell nanoparticlearched 3D interconnected graphene aerogel architectures as anodes for high-performance sodium-ion batteries. Small, 2017, 13: 1702138

44 Fang G, Wang Q, Zhou J, et al. Metal organic framework-templated synthesis of bimetallic selenides with rich phase boundaries for sodium-ion storage and oxygen evolution reaction. ACS Nano, 2019, 13: 5635-5645

45 Li X, Li W, Yu J, et al. Self-supported $\mathrm{Zn}_{3} \mathrm{P}_{2}$ nanowires-assembly bundles grafted on Ti foil as an advanced integrated electrodes for lithium/sodium ion batteries with high performances. J Alloys Compd, 2017, 724: 932-939

46 Liu W, Zhi H, Yu X. Recent progress in phosphorus based anode materials for lithium/sodium ion batteries. Energy Storage Mater, 2019, 16: 290-322

47 Ma FX, Wu HB, Xia BY, et al. Hierarchical $\beta-\mathrm{Mo}_{2} \mathrm{C}$ nanotubes organized by ultrathin nanosheets as a highly efficient electrocatalyst for hydrogen production. Angew Chem Int Ed, 2015, 54: 15395-15399

48 Wang T, Du K, Liu W, et al. Enhanced electrocatalytic activity of $\mathrm{MoP}$ microparticles for hydrogen evolution by grinding and electrochemical activation. J Mater Chem A, 2015, 3: 4368-4373

49 Yang C, Gao MY, Zhang QB, et al. In-situ activation of self-supported 3D hierarchically porous $\mathrm{Ni}_{3} \mathrm{~S}_{2}$ films grown on nanoporous copper as excellent $\mathrm{pH}$-universal electrocatalysts for hydrogen evolution reaction. Nano Energy, 2017, 36: 85-94

Acknowledgements This work was supported by the National Natural Science Foundation of China (51872334, 51874362 and 51572299), the Innovation-Driven Project of Central South University (2017CX001 and 2018CX004), and the Natural Science Foundation of Hunan Province, 
China (2018JJ1036).

Author contributions Huang $\mathrm{L}$ and Cao X contributed equally to this work. Cao $\mathrm{X}$ and Huang $\mathrm{L}$ performed the experiments and wrote the article; Yang $\mathrm{Y}$ participated in the experiments; Chen J and Kong X performed the data analysis; Cao X, Pan A, Liang S, and Cao G proposed the experimental design. All authors contributed to the general discussion.

Conflict of interest The authors declare no conflict of interest.

Supplementary information Supporting data are available in the online version of the paper.

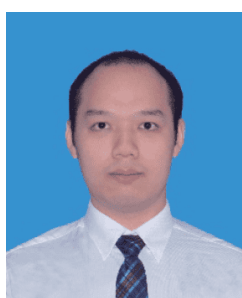

Linjun Huang received his BSc degree from the Central South University in 2016. He is currently a postgraduate student at the School of Materials Science and Engineering, Central South University. His current research focuses on MOFbased materials for electrochemical energy storage and conversion applications.

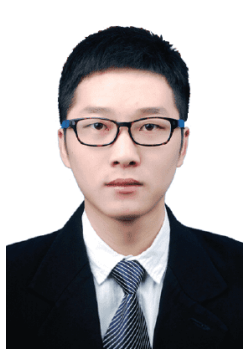

Xinxin Cao received his BSc degree in materials science and engineering from the Central South University in 2014 and $\mathrm{PhD}$ degree in materials physics and chemistry from the Central South University supervised by Prof. Shuquan Liang in 2019. His research focuses on the synthesis and application of nanomaterials and composites for clean energy storage, such as high-power/highenergy lithium ion batteries, and sodium ion batteries.

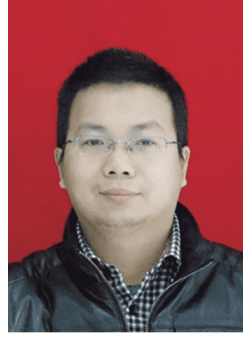

Anqiang Pan is currently a full professor in the School of Materials Science and Engineering at Central South University. He worked as visiting student at the University of Washington and Pacific Northwest National Laboratory in 2008 and 2009, respectively. Then he worked at $\mathrm{Na}$ nyang Technological University as a Research Fellow in 2011. He has published more than 100 papers in peer-reviewed journals. His current interest is rechargeable batteries, supercapacitors and catalysts.

磷掺杂碳微球封装双金属磷化物在钠离子电池和 电催化析氢中的应用

黄麟竣 ${ }^{1 \dagger}$, 曹金金金 ${ }^{1 \dagger}$, 潘安强 ${ }^{*}$, 陈婧 ${ }^{1}$, 孔祥忠 ${ }^{1}$, 杨永强 $^{1}$, 梁叔全 ${ }^{1 *}$, 曹国忠 ${ }^{2}$

摘要 过渡金属磷化物由于其独特的物理化学特性, 在钠离子电池 和电催化析氢反应领域被广泛研究. 然而, 过渡金属磷化物存在严 重团聚和动力学迟缓等问题. 本研究将双金属磷化物 $\left(\mathrm{Ni}_{2} \mathrm{P} / \mathrm{ZnP}_{4}\right)$ 嵌入到 $\mathrm{P}$ 掺杂的碳微球中, 得到的纳米材料具有结构稳定、电荷转 移快和活性位点丰富等优势. 结果表明, 结构优化的 $\mathrm{Ni}_{2} \mathrm{P} / \mathrm{ZnP}_{4}$ 复合 材料作为钠离子电池负极材料具有良好的电化学性能, 包括高比 容量、循环稳定和倍率性能佳等. 同时, $\mathrm{Ni}_{2} \mathrm{P} / \mathrm{ZnP}_{4}$ 复合材料也表 现出良好的电催化析氢性能, 其过电势为 $62 \mathrm{mV}, \mathrm{Tafel}$ 斜率为 $53 \mathrm{mV} \mathrm{dec}{ }^{-1}$, 且稳定性良好. 